\title{
All-solid-state flexible nanocomposite polymer electrolytes based on poly(ethylene oxide):lithium perchlorate using functionalized graphene
}

\author{
Sepideh Gomari ${ }^{\mathrm{a}}$, Masoud Esfandeh ${ }^{\mathrm{a} *}$, Ismaeil Ghasemi $^{\mathrm{a}}$. \\ ${ }^{a}$ Faculty of Polymer Processing, Iran Polymer and Petrochemical Institute, Pajuhesh \\ Boulevard, P.O.Box: 14965/115, Tehran, Iran. \\ *corresponding author: m.esfandeh@ippi.ac.ir \\ TEL: +98 2148662501 \\ Fax: +98 $2144787021-23$
}

\begin{abstract}
Solid polymer electrolytes (SPEs) rapidly attracted a great attention as a potential material to be used in flexible rechargeable lithium ion batteries, if an optimal match between their ionic conductivity and mechanical stability was achieved. In this work, two types of nanocomposite SPE based on poly(ethylene) oxide (PEO) and lithium perchlorate salt $\left(\mathrm{LiClO}_{4}\right)$ containing pristine graphene $(\mathrm{GnP})$ or polyethylene glycol-grafted graphene $(\mathrm{FGnP})$ were prepared. Differential scanning calorimetry (DSC) and X-ray diffraction (XRD) results revealed a reduced degree of crystallinity for nanocomposite electrolytes. The increment in amorphous phase domains was also confirmed by polarized optical microscope (POM), particularly for SPE/FGnP nanocomposites. Ionic conductivity showed one order of magnitude enhancement for $\mathrm{SPE} / \mathrm{FGnP}(0.5 \%)$ at room temperature, while mechanical stability was also improved reasonably. Polyethylene glycol grafted onto FGnP appears to play two roles: plasticizing effect to promote the segmental motion of PEO chains, and contributing in dissociation of lithium salt.
\end{abstract}


Keywords: Flexible lithium ion battery, Solid polymer electrolyte, Poly(ethylene oxide), PEG-functionalized graphene, Ionic conductivity.

\section{Introduction}

In the recent past, there is an increasing demand for flexible power sources especially lithium ion batteries (LIBs) [1-3]. Solid polymer electrolytes (SPEs) have rapidly and extensively attracted interests in this context to replace the liquid electrolytes due to their several advantages such as high specific energy and specific power, non-flammability, non-toxicity and flexibility [4,5]. However, an optimum balance between electrochemical performance and mechanical properties should be established. Poly(ethylene oxide) (PEO) is a semi-crystalline polymer which is preferred as a host polymer in SPEs due to its flexible backbone, electrochemical stability and ability to form complexes with alkali metal salts [6]. As demonstrated by many researchers, ion transport occurs only in the amorphous phase by segmental motion of polymer backbone [7-9]. It can be concluded, by reduction in the crystallization tendency of PEO, and thus development of the ion transport channels through amorphous phase, ionic conduction would be enhanced. Different approaches have been adopted to develop related materials with reduced crystallinity and higher ionic conductivity. Among them, (i) plasticized polymer electrolytes with non-aqueous, high dielectric constant organic solvents such as, propylene carbonate (PC) and ethylene carbonate (EC) [10,11], (ii) branched polymers [12,13], (iii) copolymers [14,15] and (iv) polymer blends [16,17] are extensively studied. However, these efforts to enhance room temperature ionic conductivity of polymer electrolytes have been insufficient. In addition, poor mechanical stabilities is usually another drawback of these systems [18]. 
New studies have been focused on the incorporation of fillers which can simultaneously improve the ionic conductivity and mechanical properties to form nanocomposite polymer electrolytes [3]. Using metallic or ceramic nanoparticles such as $\mathrm{TiO}_{2}, \mathrm{SiO}_{2}, \mathrm{Al}_{2} \mathrm{O}_{3}, \mathrm{MgO}$ and $\mathrm{ZnO}$ have been frequently reported in the literature [19-23]. Graphene, as a new member of carbon allotropes, is a two-dimensional lattice of carbon atoms with $\mathrm{sp}^{2}$ hybridization which has attracted great attention in the last few years due to its many extraordinary physical properties [24]. It is the strongest material ever measured and can impart mechanical strength at very low loadings if strong interfacial adhesion exists between graphene surface and polymer matrix to attain a good dispersion of graphene. Since, pristine graphene usually establishes weak interfacial interactions with polar polymers such as PEO, chemical modification is required. Grafting proper functional groups onto graphene surface is generally accomplished via a twostep procedure, which begin with graphene oxidization to produce graphene oxide (GO), as an insulating material. Subsequent modification will be performed through forming amide or carbamate ester bonds on oxygen-containing groups of GO $[25,26]$.

The effect of graphene nanoparticles on the crystallinity and ionic conductivity of PEO:NH 4 I electrolyte studied by Diwan et al. [27]. Their results showed that in addition to enhanced ionic conductivity, partial electronic conductivity was also established. Nanocomposite solid polymer electrolytes based on $\mathrm{PEO}: \mathrm{LiClO}_{4}$ modified via GO nanosheets were prepared by Gao et al. They observed 70 -fold increase in ionic conductivity $\left(4 \times 10^{-5} \mathrm{~S} \mathrm{~cm}^{-1}\right)$ at $0.6 \mathrm{wt} . \%$ of GO at room temperature [28]. Yuan and co-workers incorporated GO nanosheets into solid $\mathrm{PEO} /$ lithium salt electrolyte [29]. A maximum ionic conductivity of $2 \times 10^{-5} \mathrm{~S} \mathrm{~cm}^{-1}$ at $1 \mathrm{wt} . \%$ of GO was reported, while over $260 \%$ increase in tensile strength was also observed. In their study, by the addition of 5 wt.\% plasticizer (a combination of ethylene carbonate (EC), dimethyl 
carbonate (DMC) and diethyl carbonate (DEC)), the ionic conductivity reached the value of $1 \times 10^{-4} \mathrm{~S} \mathrm{~cm}^{-1}$. To the best of our knowledge, none of the related researches has been concerned with functionalization of graphene nanoplatelets, for example with molecules which in turn could participate in promoting the ionic conduction. Polyethylene glycol (PEG) is one of the most promising candidates of plasticizers to be used in PEO based electrolytes $[11,30]$. Nevertheless, using plasticizers has a detrimental effect on mechanical stability of SPE. It is of interest to investigate whether the incorporation of PEG-grafted graphene could increase the ionic conductivity while maintaining or even increasing the mechanical strength of the solid polymer electrolyte.

In this work, oxidized graphene nanoplatelets were chemically modified by polyethylene glycol via an amidation reaction. $\mathrm{PEO}: \mathrm{LiClO}_{4}$ polymer electrolyte system dispersed with different concentrations of pristine or functionalized graphene was prepared by solvent blending method. The effect of graphene addition and its functionalization on the crystalline structure, thermal behavior and ionic conductivity of electrolytes were studied. The mechanical properties of PEO/graphene nanocomposite thin films was also investigated. Indeed, this paper examines the correlation between the crystallinity, mechanical properties and ionic conductivity of solid polymer electrolytes with the potential application in flexible lithium ion batteries.

\section{Experimental}

\subsection{Materials}

Graphene nanoplatelets (1-5 nm thick and lateral dimension $<2 \mu \mathrm{m})$ was purchased from XG Sciences, USA, under the trade name of $x$ GnP-C750. PEO $\left(M_{W}=900,000 \mathrm{~g} \mathrm{~mol}^{-1}\right)$ was 
supplied by Scientific Polymer Products, Inc., (Ontario, NY). $\mathrm{LiClO}_{4}$ (battery grade, Aldrich) was dried under high vacuum at $40^{\circ} \mathrm{C}$ for $48 \mathrm{hr}$. Acetonitrile solvent was obtained from Merck, Germany. Sulfuric acid (98\%, Merck), nitric acid (65\%, Merck), PEG ( $\mathrm{M}_{\mathrm{W}}=400 \mathrm{~g} \mathrm{~mol}^{-1}$, Aldrich) and N,N-dicyclohexylcarbodiimide (DCC) as a dehydrating agent, were used in the functionalization procedure of graphene.

\subsection{Functionalization of graphene nanoplatelets}

Graphene nanoplatelets were chemically functionalized according to the procedure described in our previous work [31]. Initially, carboxylic acid groups were introduced onto the $\mathrm{GnP}$ nanosheets, to prepare $\mathrm{GnP}-\mathrm{COOH}$, via mixing with a 1:1 v/v mixture of $\mathrm{H}_{2} \mathrm{SO}_{4}(8 \mathrm{M})$ and $\mathrm{HNO}_{3}(8 \mathrm{M})$ and bath sonicating for $2 \mathrm{hr}$ at $60^{\circ} \mathrm{C}$. Secondly, PEG400 molecules were grafted onto $\mathrm{GnP}-\mathrm{COOH}$ through an esterification reaction at $60^{\circ} \mathrm{C}$ at the presence of $\mathrm{DCC}$ condensing agent under $\mathrm{N}_{2}$ atmosphere for $48 \mathrm{hr}$. The final product was labeled as FGnP. These procedures are schematically shown in Fig. 1. 

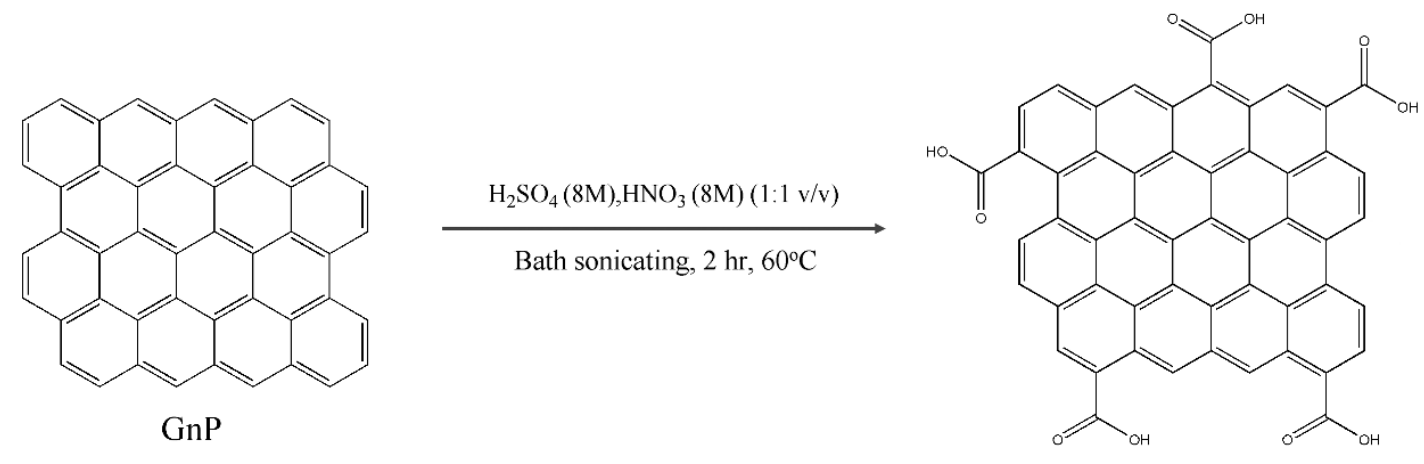

$\mathrm{GnP}-\mathrm{COOH}$

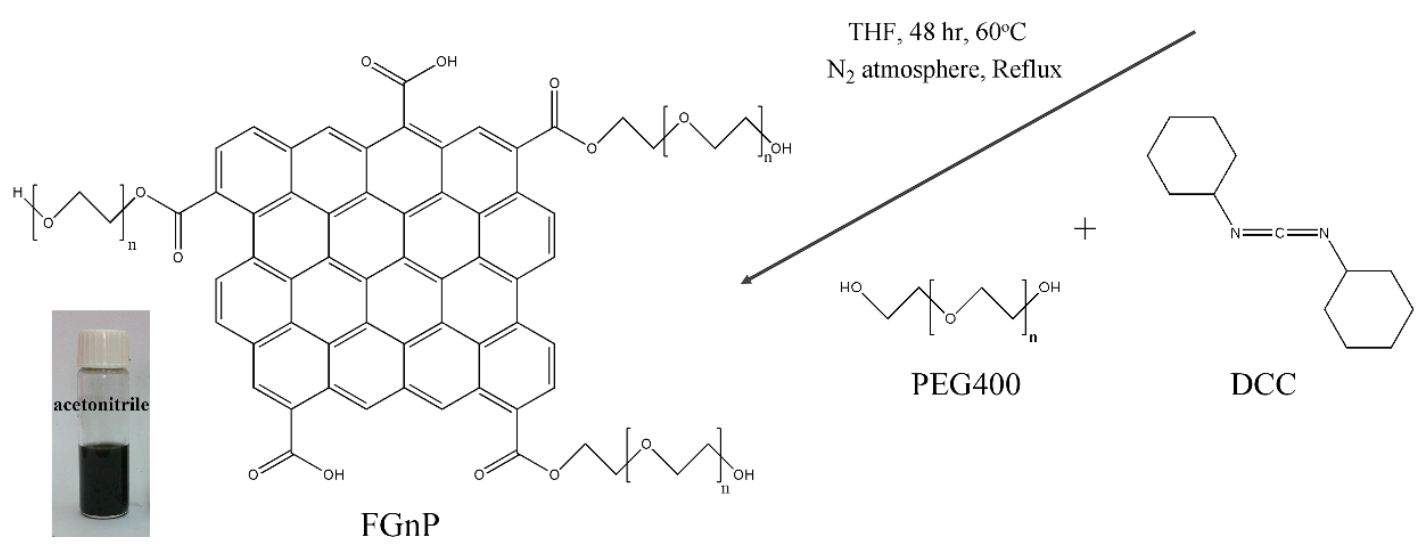

Fig. 1. The procedure for preparation of PEG-grafted graphene (FGnP) from pristine graphene $(\mathrm{GnP})$.

\subsection{Preparation of polymer electrolytes}

PEO powder and graphene nanoplatelets dried in high vacuum prior to use. PEO and $\mathrm{LiClO}_{4}$ were dissolved in acetonitrile at $50^{\circ} \mathrm{C}$. The molar ratio of ethylene oxide units (EO) to lithium cations $\left(\mathrm{Li}^{+}\right)$was fixed at $8\left([\mathrm{EO}] /\left[\mathrm{Li}^{+}\right]=8\right)$. A pre-determined amount of $\mathrm{GnP}$ (or FGnP) was added to acetonitrile and magnetically stirred overnight. After sonicating for $3 \mathrm{hr}$, the homogeneous dispersion of graphene was gradually added to polymer electrolyte solution and the mixture was continuously stirred at $50^{\circ} \mathrm{C}$ for another $24 \mathrm{hr}$. Finally, the prepared solution was cast onto Teflon petri dishes and dried at room temperature under $\mathrm{N}_{2}$ overnight and further dried at $40^{\circ} \mathrm{C}$ under vacuum for $72 \mathrm{hr}$. The films were stored in a glovebox. Solid polymer electrolyte samples containing $0.1,0.5,1$ and $3 \mathrm{wt} . \%$ of pristine or functionalized graphene are named as 
$\mathrm{SPE} / \mathrm{GnP}(\mathrm{x})$ or $\mathrm{SPE} / \mathrm{FGnP}(\mathrm{x})$, respectively, where $\mathrm{x}$ represents the weight percent of graphene nanoplatelets.

\subsection{Characterization}

Fourier transform infrared spectroscopy was conducted on a Bruker EQUINOX 55 FT-IR spectrometer, in the range of $400-4000 \mathrm{~cm}^{-1}$ and a resolution of $4 \mathrm{~cm}^{-1}$. Graphene specimens were grinded with dry $\mathrm{KBr}$ and pressed into pellets for FT-IR spectroscopy, while for polymer electrolyte samples a thin coating of dilute solution was prepared onto $\mathrm{KBr}$ pellets. Morphology of nanocomposite electrolytes was evaluated using a Tescan VEGA-II scanning electron microscope (SEM). A Carl Zeiss Jena JENAPOL polarized optical microscope (POM) was utilized to explore the crystalline structure of the samples. Before observations, each sample was melted at $120^{\circ} \mathrm{C}$, squeezed between two cover glass to form a thin film and then naturally cooled to room temperature.

X-ray diffraction (XRD) patterns were collected on Siemens D5000, Germany, using $\mathrm{Cu}$ $\mathrm{K} \alpha$ radiation source $(\lambda=0.154 \mathrm{~nm})$ operating at $40 \mathrm{kV}$ and $40 \mathrm{~mA}$. The degree of crystallinity was determined using the following equation [32]:

$$
\% X_{c}=\frac{\text { Area of the crystalline peaks }}{\text { Total area }(\text { crystalline and amorphous })} \times 100
$$

The thermal properties of the samples were determined by a DSC1 Mettler Toledo (Switzerland) differential scanning calorimeter at a heating/cooling rate of $10^{\circ} \mathrm{C} \min ^{-1}$ under nitrogen flow. Each sample was firstly heated to $100^{\circ} \mathrm{C}$, kept at this temperature for 5 min to eliminate any thermal history and then cooled to $-100^{\circ} \mathrm{C}$. The glass transition temperature and 
melting temperature of the samples were obtained from the second heating curve of DSC thermograms. The degree of crystallinity of samples calculated by equation:

$$
\% X_{c}=\Delta H_{m} / \Delta H_{m}^{\circ} \times 100
$$

where $\Delta H_{\mathrm{m}}$ is the melting enthalpy of sample and $\Delta H_{\mathrm{m}}{ }^{\circ}$ is the melting enthalpy of $100 \%$ crystalline PEO which is equal to $213.7 \mathrm{~J} \mathrm{~g}^{-1}$ [33]. Thermogravimetric analysis (TGA) were performed using a TGA/DSC1 Mettler Toledo (Switzerland) from room temperature to $700^{\circ} \mathrm{C}$ at a heating rate of $10^{\circ} \mathrm{C} \mathrm{min}^{-1}$ under nitrogen flow.

The tensile properties of PEO and PEO/graphene nanocomposite films were measured on a universal testing machine (STM-20, SANTAM, Iran) according to ASTM D882 with a strain rate of $40 \mathrm{~mm} \mathrm{~min}^{-1}$. The samples were hot pressed into thin films $(\sim 200 \mu \mathrm{m})$ and then cut into rectangular strips of the size $5 \mathrm{~mm} \times 25 \mathrm{~mm}$. The reported data are the average of 3 replicates.

The electrical conductivity of $\mathrm{PEO} / \mathrm{GnP}$ and $\mathrm{PEO} / \mathrm{FGnP}$ nanocomposites was evaluated by a four-point probe method (BK Precision, USA). Measurements were repeated three times at different points of the sample and the average electrical conductivity was reported.

The ionic conductivity of SPEs was measured by sandwiching the samples between two stainless steel blocking electrodes. The measurements were performed using AUTO-LAB PGSTAT potentiostat/galvanostat analyzer equipped with a frequency response analyzer (FRA) module between $1 \mathrm{MHz}$ and $10 \mathrm{~Hz}$. The ac amplitude was $20 \mathrm{mV}$. The room temperature ionic conductivity $(\sigma)$ of electrolyte samples obtained from Nyquist plots using the following equation:

$$
\sigma=\frac{d}{A \times R}
$$

Here, $d$ is the thickness of electrolyte film, $A$ is the area of the electrode and $R$ is the 
electrolyte resistance acquired from the impedance spectrum.

\section{Results and Discussion}

FT-IR spectroscopy was utilized as the primary analytical technique to confirm the functionalization of graphene nanoplatelets and the related spectra (pristine $\mathrm{GnP}, \mathrm{GnP}-\mathrm{COOH}$, FGnP and neat PEG400) are given in Fig. 2. GnP-COOH in Fig. 2b shows a new peak at 1712 $\mathrm{cm}^{-1}$ in comparison to pure $\mathrm{GnP}$ in Fig. 2a. This peak which is associated with $\mathrm{C}=\mathrm{O}$ carbonyl group, accompanying the stretching vibration of $-\mathrm{OH}$ hydroxyl group appeared at $3443 \mathrm{~cm}^{-1}$, can be expressed as an indication of the presence of carboxylic acid groups on the $\mathrm{GnP}-\mathrm{COOH}$ sample [25]. In general, $\mathrm{C}=\mathrm{C}$ stretching of aromatic rings absorbs in the $1650-1430 \mathrm{~cm}^{-1}$ range [34]. The peak around $1619 \mathrm{~cm}^{-1}$ is originated from the carbon skeleton ring vibration, $\mathrm{O}-\mathrm{H}$ bending vibrations or oxygen surface compounds, like cyclic ethers $[25,35]$. The shoulder at $1576 \mathrm{~cm}^{-1}$ may represent unoxidized aromatic regions of GnP-COOH [35]. In Fig. 2c, a new absorption band emerged at $1102 \mathrm{~cm}^{-1}$ which is attributed to $\mathrm{C}-\mathrm{O}-\mathrm{C}$ ether groups of PEG. The blue shift of carbonyl band to $1746 \mathrm{~cm}^{-1}$ affirms the formation of ester linkages [36]. In addition, the intensity of C-H stretching of alkyl groups of PEG (at 2856 and $2932 \mathrm{~cm}^{-1}$ ) and hydroxyl absorption band of the end groups of PEG (at $3443 \mathrm{~cm}^{-1}$ ) has been enhanced. Interestingly, the intensity of the peak at $1623 \mathrm{~cm}^{-1}$ is strengthened and the peak at $1574 \mathrm{~cm}^{-1}$ is weakened after functionalization with PEG. In light of the foregoing, it can be admitted that the chemical grafting of PEG onto graphene nanosheets has been accomplished successfully. 


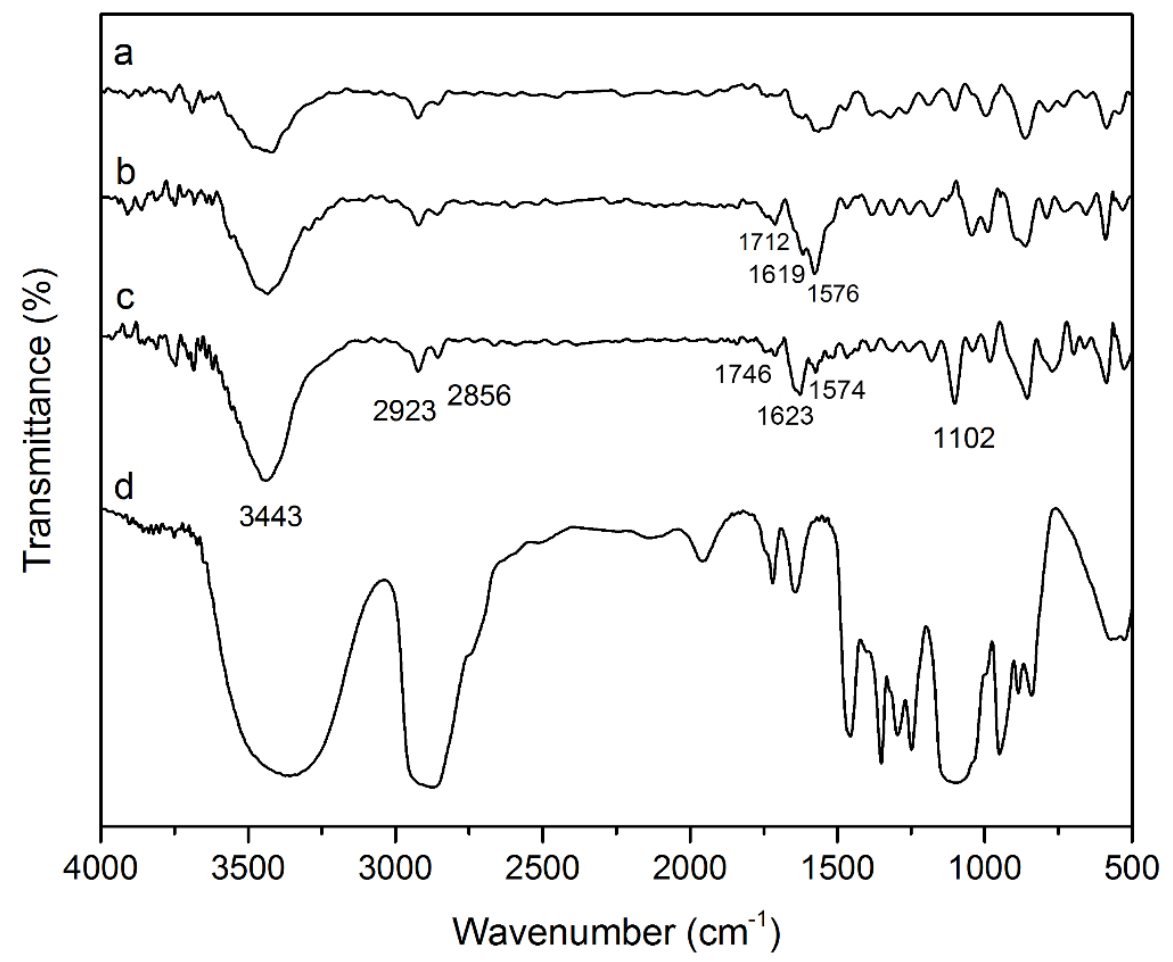

Fig. 2. FT-IR spectra of (a) neat GnP, (b) GnP-COOH, (c) FGnP and (d) pure PEG400.

The exfoliation of graphene nanoplatelets into few layers, and even down to single layers would provide the advantage of large surface area per unit volume of these nanoplatelets. Hence, it is of crucial interest to engineer the morphology of nanocomposites at the nanoscale, for example via chemical functionalization. In order to explore the effect of PEG modification on the dispersion state of graphene nanosheets, typical SEM micrographs of fractured surface of SPEs containing 0.5 wt.\% of $\mathrm{GnP}$ and $\mathrm{FGnP}$ are illustrated in Fig. 3a and 3b, respectively. Serious aggregations of $\mathrm{GnP}$ nanosheets could be observed in Fig. 3a, while a fine dispersion of FGnP was discovered in Fig. 3b. This can be an indication of high affinity and existence of strong interfacial interactions between $\mathrm{FGnP}$ and PEO matrix. The inset of Fig. $3 \mathrm{~b}$ belongs to polymer electrolyte with 3 wt.\% of FGnP. As can be seen, at higher concentrations of FGnP, 
some aggregations would appear.
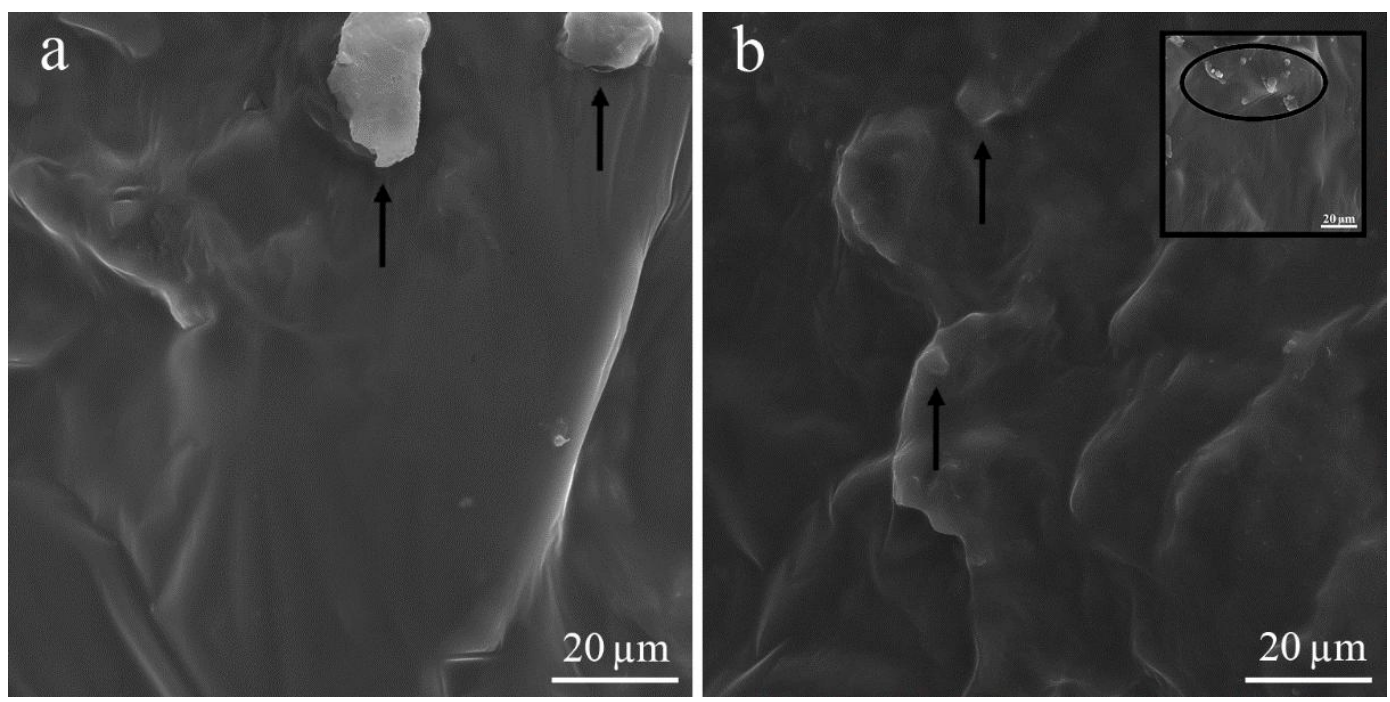

Fig. 3. SEM micrographs of cryofractured surfaces of a) $\mathrm{SPE} / \mathrm{GnP}(0.5)$ and b) $\mathrm{SPE} / \mathrm{FGnP}(0.5)$, the inset shows SPE/FGnP(3) sample.

Fig. 4 displays the surface morphology of SPE and its nanocomposites containing various amounts of GnP or FGnP. The neat electrolyte in Fig. 4a, shows relatively rough surface which could be ascribed to packed crystalline regions of PEO. In Fig. 4b to 4e (SPE/GnP(x) samples), rough surfaces were observed and crystalline domains could be easily discovered, although an increase in amorphous regions was also detected. On the other hand, for SPE/FGnP(x) nanocomposites a smooth surface at lower contents of FGnP (Fig. 4f and 4g) and a rough surface at higher amounts (Fig. 4h and 4i) was observed. It is noteworthy that the most smooth surface morphology belongs to $\mathrm{SPE} / \mathrm{FGnP}(0.5)$ sample shown in Fig. $4 \mathrm{~g}$. This can be attributed to the lower crystalline phase due to well dispersion and the hydrogen interactions between PEG groups of FGnP and ether oxygen groups in $\mathrm{PEO}$ [37]. A rough to smooth surface transition after the addition of nanoparticles was also disclosed in the literature as an indication of decrease in crystallinity [38,39]. However, a gradual change from smooth to rough surface upon a further 
increase in FGnP concentration (Fig.s 4h and 4i), may be ascribed to undesirable dispersion and presence of large agglomerations of FGnP.

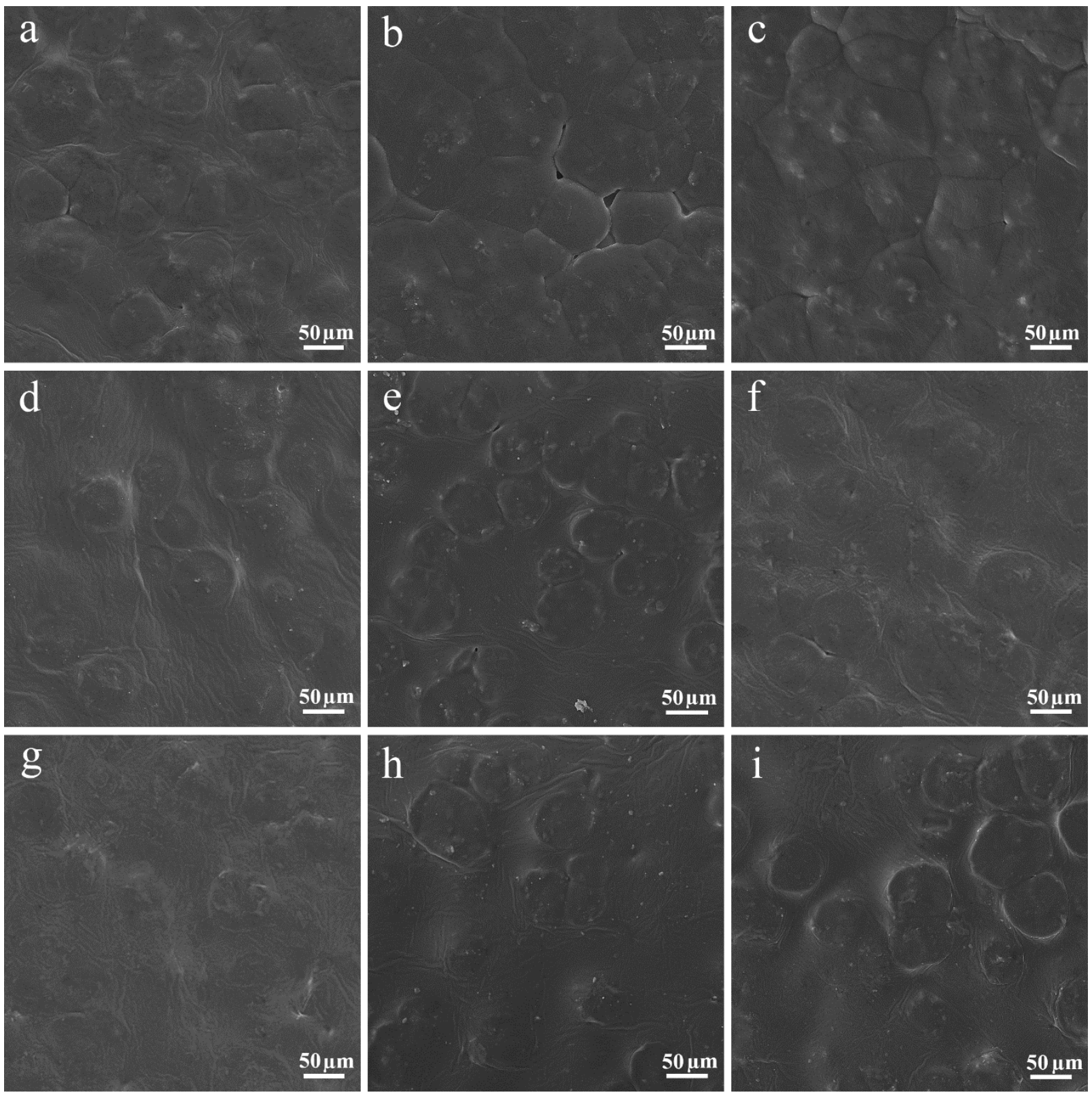

Fig. 4. Surface $\mathrm{SEM}$ images of a) $\mathrm{SPE}$, b) $\mathrm{SPE} / \mathrm{GnP}(0.1)$, c) $\mathrm{SPE} / \mathrm{GnP}(0.5)$, d) $\mathrm{SPE} / \mathrm{GnP}(1)$, e) $\mathrm{SPE} / \mathrm{GnP}(3)$, f) SPE/FGnP(0.1), g) SPE/FGnP(0.5), h) SPE/FGnP(1), i) SPE/FGnP(3). 
The normalized XRD patterns of neat SPE and nanocomposites containing different loadings of GnP or FGnP are illustrated in Fig. 5a and 5b, respectively. The characteristic peaks of crystalline PEO are observed for all samples at $2 \theta=19.2^{\circ}$ and $23.4^{\circ}$, which are related to (120) and (112) planes, respectively [23]. As can be seen, the crystalline peaks intensity slightly reduced by incorporation of $\mathrm{GnP}$ and more considerably reduced after $\mathrm{FGnP}$ addition. Determination of crystallinity of electrolytes based on XRD method was performed according to Equation 1 and the results are summarized in Table 1. Nanocomposite electrolytes showed lower crystallinity in comparison to neat SPE. However, FGnP had a more prominent role to impede the crystallization of PEO and the lowest crystallinity was observed for SPE/FGnP(0.5) and SPE/FGnP(1) samples. The insets of Fig. 5 depicts the XRD patterns of related graphene nanoplatelets. As can be seen, $\mathrm{GnP}$ shows an intense peak at $2 \theta=26.3^{\circ}$, while after chemical functionalization with PEG, this peak has become weaker and broader. Indeed, it is an expectable observation, since PEG is attached to the carboxylic acid groups of $\mathrm{GnP}-\mathrm{COOH}$ which are present at the edges of oxidized nanosheets [40], not on the basal plane to expand the d-spacing after PEG grafting. Interestingly, no characteristic peak of graphene nanoplatelets was discovered in the XRD patterns of SPE nanocomposites. It could be attributed to the low concentration of graphene nanoplatelets and probable overlapping with weak peaks of pure PEO around $2 \theta=26.3^{\circ}$ and $27^{\circ}[28,41]$. 

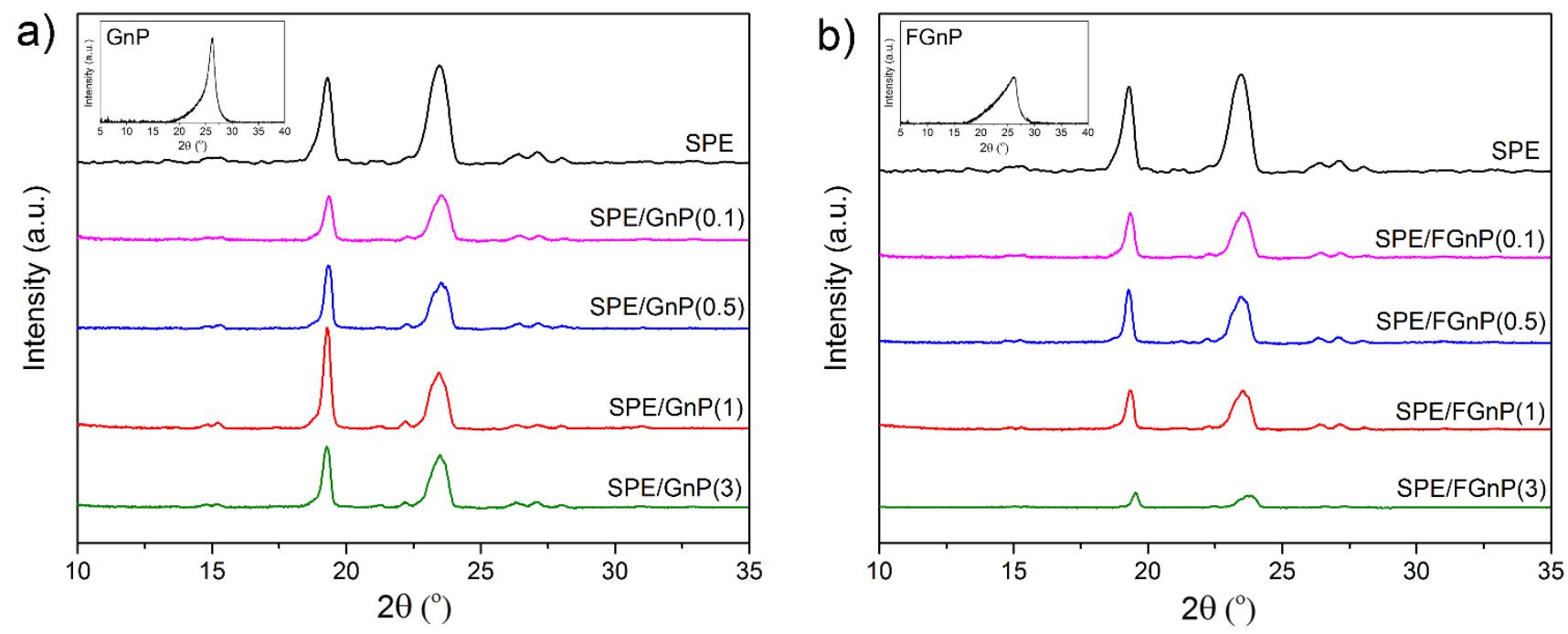

Fig. 5. Normalized XRD patterns of a) SPE/GnP(x) and b) SPE/FGnP(x) nanocomposites. Insets show pure GnP and FGnP.

Table 1. Degree of crystallinity of nanocomposite electrolytes based on XRD.

\begin{tabular}{lc}
\hline Sample & Degree of Crystallinity (\%) \\
\hline SPE & 47.6 \\
SPE/GnP(0.1) & 42.0 \\
SPE/GnP(0.5) & 44.6 \\
SPE/GnP(1) & 46.5 \\
SPE/GnP(3) & 44.3 \\
SPE/FGnP(0.1) & 42.2 \\
SPE/FGnP(0.5) & 39.3 \\
SPE/FGnP(1) & 39.7 \\
SPE/FGnP(3) & 41.5 \\
\hline
\end{tabular}

Crystallization behavior of samples was evaluated by DSC analysis and some useful results are indicated in Fig. 6 as a function of filler concentration. The crystallization temperature $\left(T_{\mathrm{c}}\right)$ remained nearly unchanged after incorporation of filler in both of SPE/GnP and SPE/FGnP nanocomposites, as shown in Fig. 6a. In general, nanoparticles act as heterogeneous nucleating 
agents to increase the $T_{\mathrm{c}}$ of polymer matrix [42,43]. However, a different crystallization behavior was also reported for PEO in the literature, i.e. nanoparticles decreased the $T_{\mathrm{c}}$ to hinder the PEO crystallization [44-46]. In the present study, it seems that neither GnP nor FGnP have significant effect on the nucleation density of PEO crystallites.

According to Fig. 6b, incorporation of GnP into SPE, did not considerably affect the melting temperature $\left(T_{\mathrm{m}}\right)$ of samples. On the other hand, for SPE/FGnP nanocomposites $T_{\mathrm{m}}$ decreased as FGnP concentration increased upto $0.5 \mathrm{wt} . \%$, and then starts to increase. The reduction in $T_{\mathrm{m}}$ is probably related to the increment of defect density in the crystallites of PEO due to better dispersion and stronger interactions of FGnP nanosheets with PEO chains. As demonstrated from SEM images, at higher amounts of FGnP, they form aggregates which deteriorate their effectiveness as barriers to crystal growth. In a similar way, the degree of crystallinity $\left(X_{\mathrm{c}}\right)$ of SPE/FGnP nanocomposites reached a minimum at $0.5 \mathrm{wt} . \%$ of $\mathrm{FGnP}$ as can be seen in Fig. 6c. Another interesting point is that SPE/FGnP nanocomposites show a lower $X_{\mathrm{c}}$ in comparison to $\mathrm{SPE} / \mathrm{GnP}$ samples. These observations are consistent with XRD results of crystallinity. 

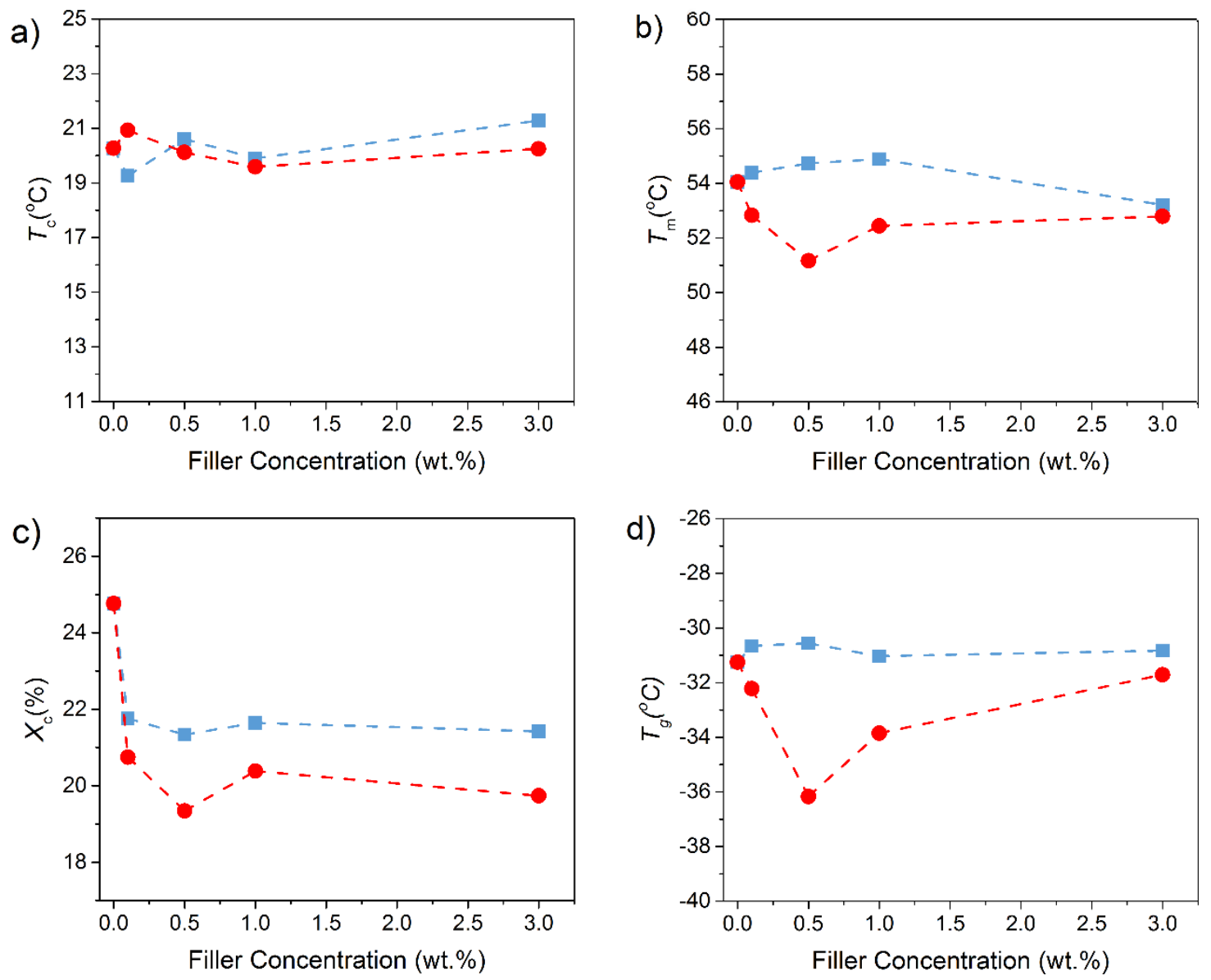

Fig. 6. The obtained results from DSC analysis: a) crystallization temperature $\left(T_{\mathrm{c}}\right)$, b) melting temperature $\left.\left(T_{\mathrm{m}}\right), \mathrm{c}\right)$ degree of crystallinity $\left(X_{\mathrm{c}}\right)$, and d) glass transition temperature ( $T_{\mathrm{g}}$ of SPE and its nanocomposites containing GnP (solid square) and FGnP (solid circle) as a function of filler content.

Glass transition temperature $\left(T_{\mathrm{g}}\right)$ of the samples which is an indication of the mobility of polymer chains was determined and represented in Fig. 6d. It seems that GnP addition has no remarkable effect on the $T_{\mathrm{g}}$ of $\mathrm{SPE} / \mathrm{GnP}$ samples, whereas, a minimum $T_{\mathrm{g}}$ of $-36.2^{\circ} \mathrm{C}$ was detected for $\mathrm{SPE} / \mathrm{FGnP}(0.5)$ sample which is $5^{\circ} \mathrm{C}$ lower than that of the neat SPE. This means that PEO chains has a higher mobility in the presence of FGnP nanosheets. The disruption of crystallization and compact molecular packing and increasing in the free volume of matrix are 
previously reported as common reasons for $T_{\mathrm{g}}$ reduction after nanoparticles incorporation $[29,47]$. However, in our work the plasticizing effect of PEG molecules grafted onto graphene nanoplatelets is assumed to be another effective reason.

Polarized optical microscopy is a useful instrument to gain a direct insight into crystalline structure of SPEs. Fig. 7 shows the POM images of neat PEO, SPE and nanocomposite electrolytes loaded with 0.1 and 1 wt.\% of $\mathrm{GnP}$ and $\mathrm{FGnP}$, for brevity. A "Maltese-cross" extinction pattern which is typical of spherulites was observed for PEO in Fig. 7a [48]. For SPE sample in Fig. 7b, a closely stacks of spherulites due to impingement of adjacent spherulites can be visualized. In addition, a coarse texture which is ascribed to lamellae bundles is formed. A reduction in nucleation sites and an increment of spherulite size could be detected in comparison to neat PEO. However, no further changes in the number of nucleation sites and the size of spherulites was found upon the incorporation of $\mathrm{GnP}$ or $\mathrm{FGnP}$ in Fig.s $7 \mathrm{c}$ to $7 \mathrm{f}$ which is in accordance with $T_{\mathrm{c}}$ values. It is worthy of remark that the lamellae bundles arrange loosely around the nuclei by the addition of graphene nanoplatelets specially for the SPE/FGnP(1) sample in Fig. 7f. The variation in crystalline structure of electrolytes can be mainly attributed to the suppression of spherulitic growth in the presence of graphene nanosheets. Since PEG grafted molecules on FGnP filler establishes intense interactions with PEO chains, it has a higher hindrance effect on the crystallization of SPEs, as was also concluded by DSC analysis. Some aggregations can be found in the samples containing GnP, while in the case of FGnP rarely aggregations was observed. 

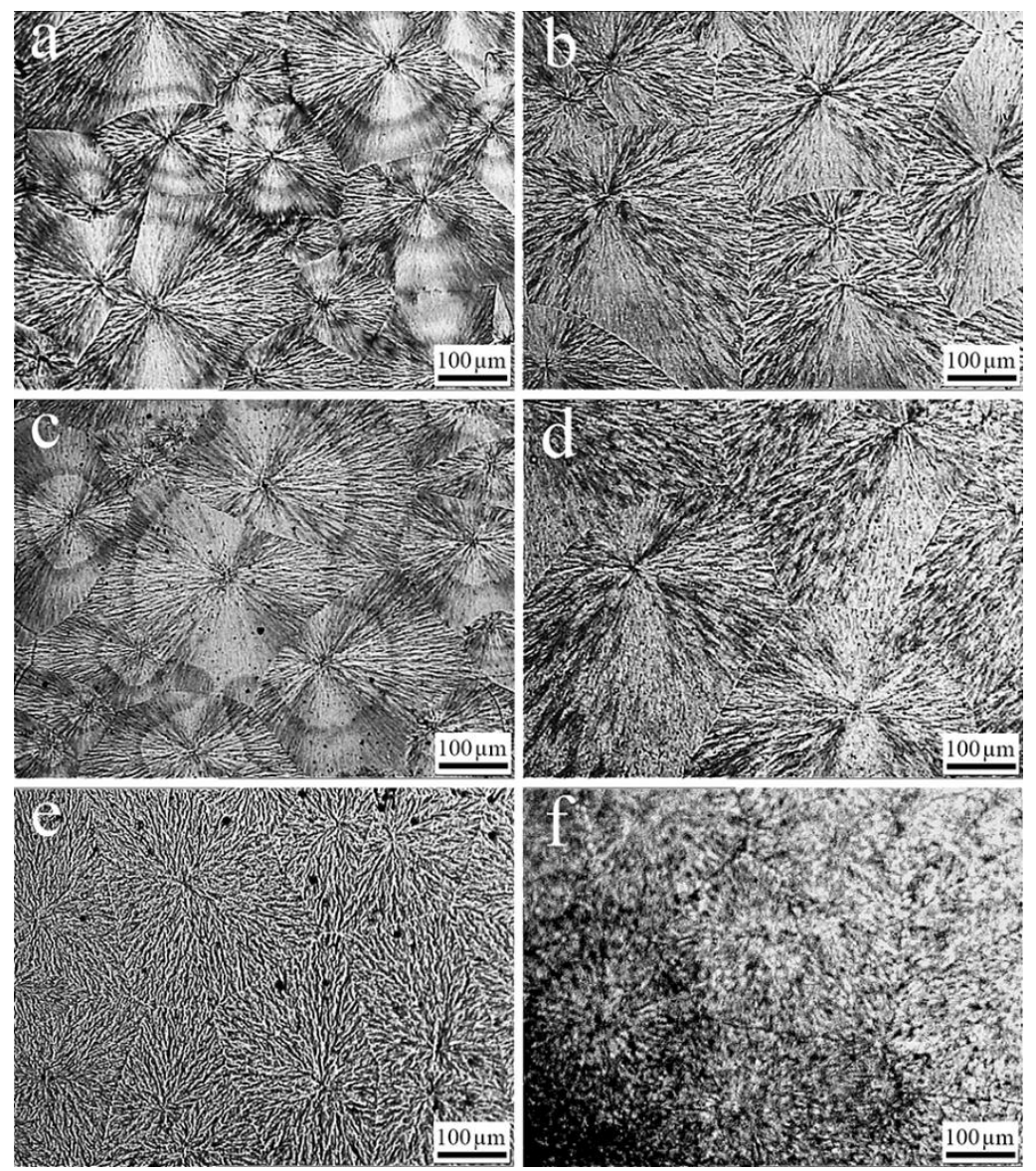

Fig. 7. Polarized optical microscopy images of a) PEO, b) SPE, c) SPE/GnP(0.1), d) SPE/FGnP (0.1), e) $\mathrm{SPE} / \mathrm{GnP}(1)$ and f) SPE/FGnP(1).

In order to investigate whether $\mathrm{GnP}$ and $\mathrm{FGnP}$ could have an impressive effect on the fraction of dissociated free ions, FT-IR spectroscopy was performed. $v_{4}$ vibration of $\mathrm{ClO}_{4}{ }^{-}$ions which appears at the region $600-650 \mathrm{~cm}^{-1}$, is related to ion-ion interactions in PEO: $\mathrm{LiClO}_{4}$ electrolytes and employed to calculate the dissociation factor of lithium salt $[49,50] . \mathrm{ClO}_{4}{ }^{-}$shows two peaks in this region which the first one around $620-625 \mathrm{~cm}^{-1}$ is associated with the free ions while the second one in the range $630-635 \mathrm{~cm}^{-1}$ represents $\mathrm{Li}^{+}-\mathrm{ClO}_{4}^{-}$contact ion pairs. It is common that, the ratio of integrated areas under the peak in the range $620-625 \mathrm{~cm}^{-1}$ to the total area is assigned to the dissociation factor. As can be seen in Fig. 8, the dissociation factor of the 
neat SPE is $74.4 \%$. Although by $\mathrm{GnP}$ addition the dissociation factor rises slightly at first, it reduces to values lower than that of the neat SPE at higher contents. This could be related to the barrier effect of GnP agglomerations which keeps PEO chains away from the contact-ion pairs and prevents their interaction. FGnP incorporation, on the other hand, has led to a considerable increase in the fraction of free ions as it reached a maximum of $93.8 \%$ at $0.5 \mathrm{wt} . \%$ of FGnP. It is supposed that ether groups in PEG molecules which have a similar structure as PEO, could be coordinated with $\mathrm{Li}^{+}$cations and thus FGnP nanosheets facilitate the dissociation of lithium salt. The reduction in dissociation factor at higher contents of FGnP can be explained by the reduction in the effective interfacial area between $\mathrm{FGnP}$ and $\mathrm{LiClO}_{4}$ due to the formation of aggregation of nanosheets.

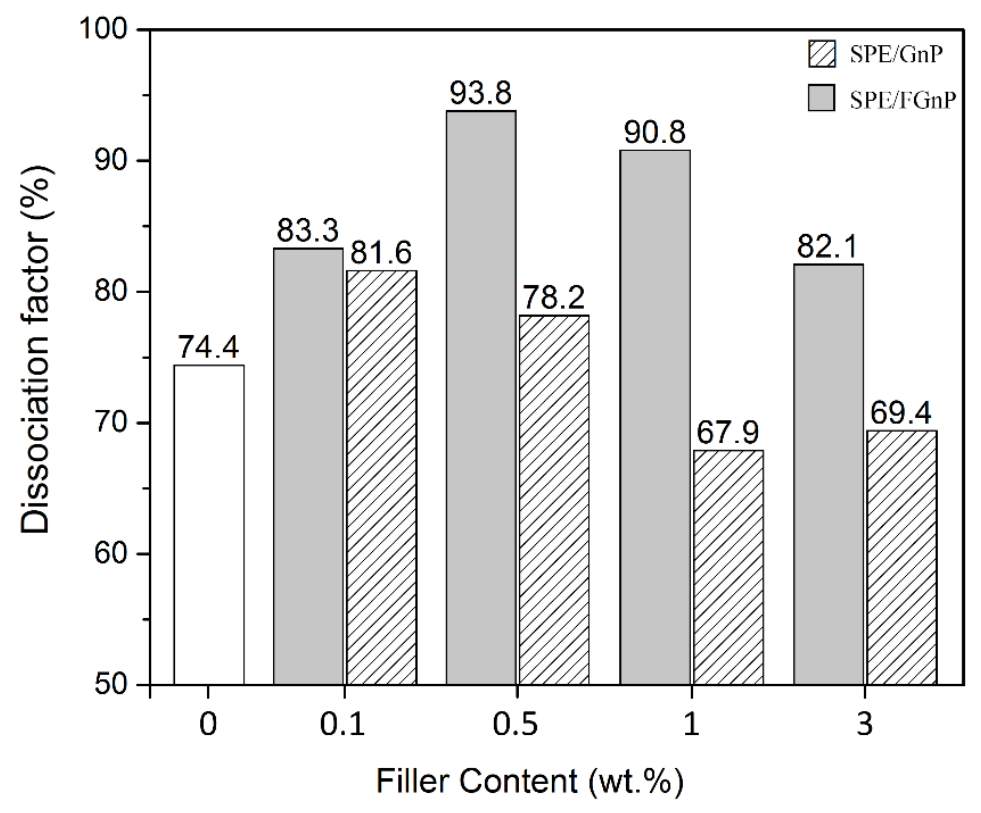

Fig. 8. Dissociation factor of salt ions (fraction of free anions) based on FT-IR analysis for SPE/GnP and SPE/FGnP nanocomposites with various filler content.

Fig. 9 displays the ionic conductivity of $\mathrm{SPE} / \mathrm{GnP}(\mathrm{x})$ and $\mathrm{SPE} / \mathrm{FGnP}(\mathrm{x})$ nanocomposite 
electrolytes with various $\mathrm{x}$ values. Before the addition of nanosheets, neat SPE shows the ionic conduction of $1.31 \times 10^{-6} \mathrm{~S} \mathrm{~cm}^{-1}$. By incorporation of $0.1 \mathrm{wt} \% \mathrm{GnP}$, the ionic conductivity increased to $8.19 \times 10^{-6} \mathrm{~S} \mathrm{~cm}^{-1}$ and remained almost constant upon increasing in $\mathrm{GnP}$ concentration up to $3 \mathrm{wt} \%$. For $\mathrm{SPE} / \mathrm{FGnP}(\mathrm{x})$ samples, the ionic conductivity passed through a maximum of $2.53 \times 10^{-5} \mathrm{~S} \mathrm{~cm}^{-1}$ at $0.5 \mathrm{wt} . \%$ of $\mathrm{FGnP}$ which is one order of magnitude higher than that of neat SPE, but then reduced to $9.5 \times 10^{-6} \mathrm{~S} \mathrm{~cm}^{-1}$ for $\mathrm{SPE} / \mathrm{FGnP}(3)$. There are similar results which state the increment in ionic conductivity and reduction of crystallinity by addition of nanoparticles. However, the reported data are lower than the results of the current study. For example, Zhou et al. have studied the effect of functionalized multiwalled carbon nanotubes on the crystallinity and ionic conductivity of $\mathrm{PEO}-\mathrm{LiClO}_{4}$ electrolyte and found that by the addition of $1 \mathrm{wt} . \%$ of nanotubes the crystallinity of the polymer electrolyte reduced, while the ionic conductivity increased hardly by a factor of 3.3 to reach $7.3 \times 10^{-7} \mathrm{~S} \mathrm{~cm}^{-1}$ [51]. In another study, a 6-fold ion conductivity enhancement in PEO:LiTFSI electrolyte was reported by Sun et. al at $30^{\circ} \mathrm{C}$ after the addition of $20 \mathrm{wt} . \%$ fullerene nanoparticles $\left(2.5 \times 10^{-6} \mathrm{~S} \mathrm{~cm}^{-1}\right)$ [47]. It should be considered that a descending trend of Young's modulus was detected after incorporation of nanoparticles. The maximum ionic conductivity of $4 \times 10^{-5} \mathrm{~S} \mathrm{~cm}^{-1}$ at $0.6 \mathrm{wt} . \%$ of GO [28] and $2 \times 10^{-5} \mathrm{~S} \mathrm{~cm}^{-1}$ at $1 \mathrm{wt} . \%$ of GO [29] for PEO: $\mathrm{LiClO}_{4}$ systems was also previously reported in the literature. 


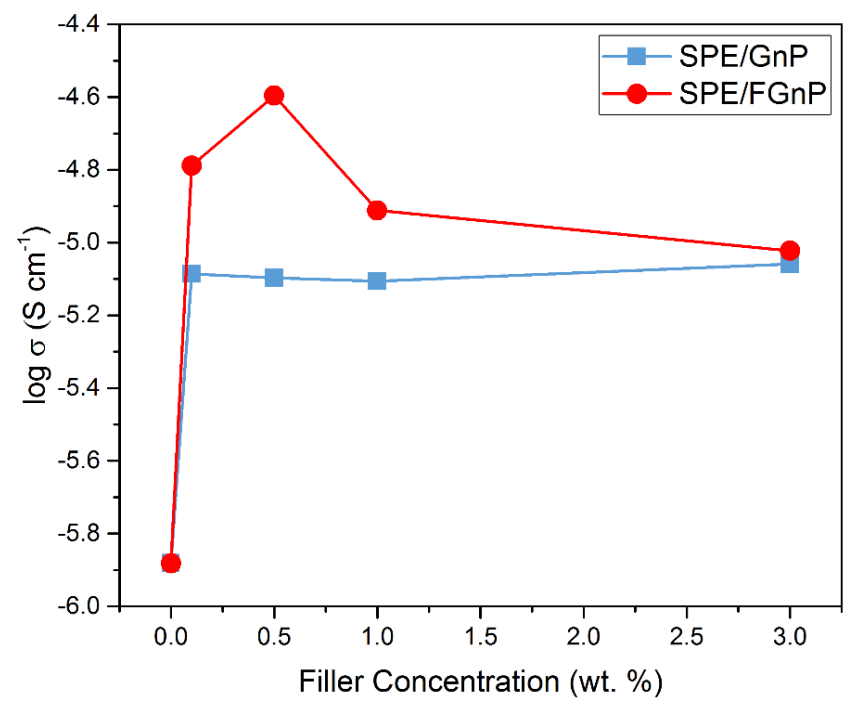

Fig. 9. The ionic conductivity of SPE/GnP and SPE/FGnP nanocomposites with various filler loadings at room temperature.

The ionic conductivity in a solid polymer electrolyte is correlated with several parameters which can be explained by the following relation [52]:

$$
\sigma=\sum n_{i} z_{i} \mu_{i}
$$

where $n_{\mathrm{i}}$ is the number of charge carriers, $z_{\mathrm{i}}$ is the ionic charge and $\mu_{\mathrm{i}}$ is the mobility of ions. In polymer/salt electrolyte systems, $n_{\mathrm{i}}$ and $\mu_{\mathrm{i}}$ are greatly affected by the characteristics of each component, e.g. the concentration of free ions of alkaline salt and the mobility of polymer chains, respectively. Considering this relation, the coming after explanations could be suggested for the enhanced ionic conductivity in the presence of $\mathrm{FGnP}$ nanoplatelets, which are also captured schematically in Fig. 10:

- Increasing the content of amorphous phase: As detected from DSC analysis, blending $\mathrm{GnP}$ or FGnP with PEO hinders the reorganization of polymer chains to cause a reduction in PEO crystallinity. This hindrance effect becomes more pronounced in the 
case of FGnP due to better dispersity which ensures an ultra-large surface area of FGnP nanoplatelets in the matrix. Thereby, a higher number of PEO chains would involve hydrogen bonds with PEG grafted graphene sheets. The SPE/FGnP(0.5) sample shows the lowest degree of crystallinity, i.e. the highest content of amorphous phase which is responsible for ionic conduction.

- Enhanced concentration of free ions: Calculation of dissociation factor of lithium salt demonstrated that $\mathrm{FGnP}$ promotes the fraction of free $\mathrm{ClO}_{4}{ }^{-}$anions, while $\mathrm{GnP}$ has no beneficial effect. It can be deduced that PEG molecules present on the graphene surface efficiently contribute in dissociation of lithium salt to increase the charge carrier concentration by weakening the bond between the contact ion pairs. The SPE/FGnP sample showed the greatest fraction of free ions according to Fig. 8 .

- The reduction in $T_{\mathrm{g}}$ : With the introduction of FGnP, it was discovered that $T_{\mathrm{g}}$ drops to a minimum for $\mathrm{SPE} / \mathrm{FGnP}(0.5)$ sample. In spite of the fact that rigid nature of graphene sheets might reduce the segmental motion of polymer chains to increase $T_{\mathrm{g}}[53,54]$, the reduction in $T_{\mathrm{g}}$ suggests the higher chain mobility and larger free volume in the presence of FGnP. Indeed, surface properties of filler play a determinant role in the reduction or increment of $T_{\mathrm{g}}$. Until the polymer-filler interaction is attractive, the dynamics of polymer especially in the vicinity of filler surface would be slowed down and an increase in $T_{\mathrm{g}}$ is expectable. However, for repulsive interaction an accelerated dynamic and thus a decreased $T_{\mathrm{g}}$ is validated $[55,56]$. Since FGnP establishes strong attractive hydrogen bonds with PEO chains, $T_{\mathrm{g}}$ was assumed to show increasing trend. Therefore, the reduction of $T_{\mathrm{g}}$ supports the hypothesis that PEG molecules grafted onto graphene could act as good plasticizer for solid polymer electrolytes based on PEO to 
increase the flexibility of PEO chains.

- Increasing the possible positions for $\mathrm{Li}^{+}$hopping: It is declared that $\mathrm{Li}^{+}$cations can find new low-energy paths along the interface of carbon based filler and polymer matrix due to strong affinity between electron cloud and positive lithium ions [50,57]. Furthermore, PEG molecules grafted onto graphene provide further ion conducting channels inside the nanocomposite polymer electrolyte. In this way, the probability for the occurrence of $\mathrm{Li}^{+}$hopping and transport within the electrolyte film increases.

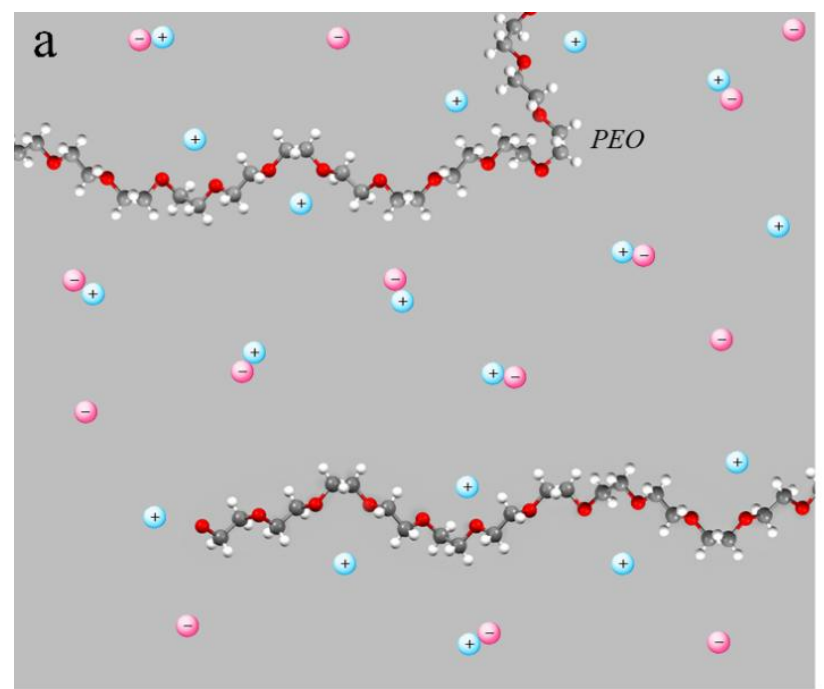

$+\mathrm{Li}^{+}$

$\ominus \mathrm{ClO}_{4}^{-}$

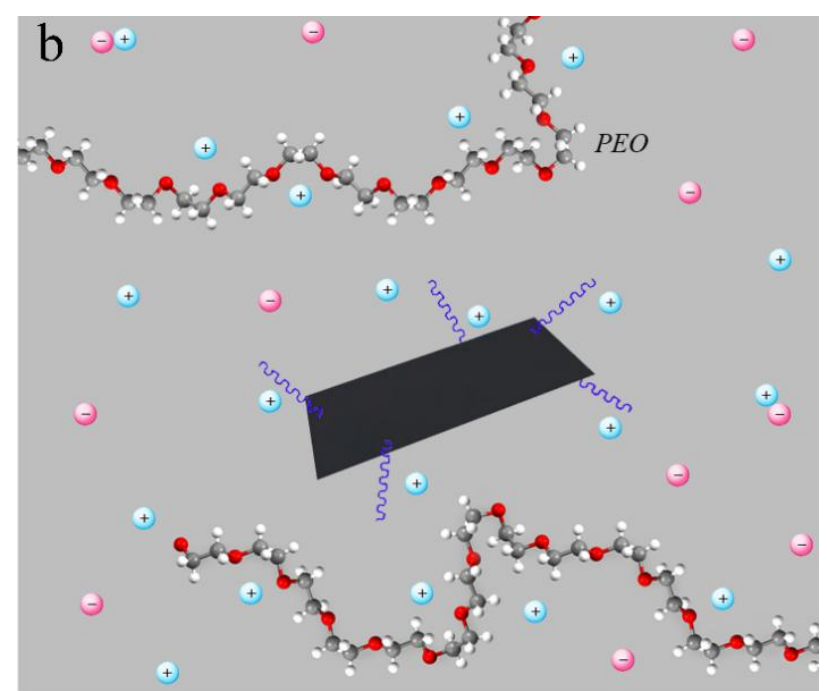

Graphene nanoplatelet urron $P E G$

Fig. 10. Schematics of PEO: $\mathrm{LiClO}_{4}$ electrolytes without (a) and with (b) FGnP.

The electrical conductivity of nanocomposite samples was evaluated and reported in Table 2. In order to avoid short-circuiting in the battery, it is of great necessity to examine the electrical properties of polymer electrolyte films and ensure about their insulating properties. As can be seen, none of the nanocomposites show electrical percolation behavior and the value of electrical 
conductivity of all samples is much lower than a conductive material. Previous studies have been suggested that polymer nanocomposites containing graphene nanoplatelets exhibit very low percolation threshold, if rather a conductive network was constructed [58]. High aspect ratio and high surface area of graphene facilitates the formation of a conducting network. However, a nearly full exfoliation is required to provide plane-to-plane contact between the nanosheets [59]. Since large aggregations of $\mathrm{GnP}$ was obtained in $\mathrm{PEO} / \mathrm{GnP}$ nanocomposites, no network structure could be developed and thus no transition from an electrical insulator to an electrical conductor was observed. Note that the inherent electrical conductivity of graphene is lost after oxidation and thermal or chemical reduction is required to restore the $\mathrm{sp}^{2}$ carbon structure $[60,61]$. Thus, it was expected that FGnP could not also propagate the electrical conduction in spite of the well dispersion of these nanoplatelets.

Table 2. Electrical conductivity of neat $\mathrm{PEO}, \mathrm{PEO} / \mathrm{GnP}(\mathrm{x})$ and $\mathrm{PEO} / \mathrm{FGnP}(\mathrm{x})$ nanocomposites.

\begin{tabular}{ll}
\hline Sample & Electrical conductivity $\left(\mathrm{S} \mathrm{cm}^{-1}\right)$ \\
\hline $\mathrm{PEO}$ & $7.74 \times 10^{-12}$ \\
$\mathrm{PEO} / \mathrm{GnP}(0.1)$ & $1.14 \times 10^{-10}$ \\
$\mathrm{PEO} / \mathrm{GnP}(0.5)$ & $6.95 \times 10^{-11}$ \\
$\mathrm{PEO} / \mathrm{GnP}(1)$ & $7.33 \times 10^{-11}$ \\
$\mathrm{PEO} / \mathrm{GnP}(3)$ & $2.20 \times 10^{-11}$ \\
$\mathrm{PEO} / \mathrm{FGnP}(0.1)$ & $5.40 \times 10^{-11}$ \\
$\mathrm{PEO} / \mathrm{FGnP}(0.5)$ & $6.00 \times 10^{-11}$ \\
$\mathrm{PEO} / \mathrm{FGnP}(1)$ & $6.62 \times 10^{-11}$ \\
$\mathrm{PEO} / \mathrm{FGnP}(3)$ & $9.40 \times 10^{-11}$ \\
\hline
\end{tabular}

As mentioned previously, one of the most important properties of SPE films during the practical application is their mechanical stability. In this study, the mechanical properties of neat $\mathrm{PEO}, \mathrm{PEO} / \mathrm{GnP}(\mathrm{x})$ and $\mathrm{PEO} / \mathrm{FGnP}(\mathrm{x})$ nanocomposites were studied and reported in Table 3 . The 
typical stress-strain curve of the samples are also illustrated in Fig.11. As can be seen, all samples showed a plastic deformation with a yield point and necking, and then ruptured at an ultimate strain. By exploiting the slopes of stress-strain diagrams at very low strains, Young's moduli was calculated. The stiffness of the nanocomposites was improved by the incorporation of various concentrations of graphene nanoparticles. The maximum increase was $74 \%$ and $83 \%$ for $\mathrm{GnP}$ and $\mathrm{FGnP}$ at $0.5 \mathrm{wt} \%$, respectively. The grafting of PEG molecules onto graphene nanoplatelets seems to have little effect on the Young's modulus. On the other hand, tensile strength, toughness and elongation at break demonstrated significant dependency on the graphene functionalization and interfacial interactions. Indeed, the mechanical properties were markedly improved in the case of samples containing FGnP compared to GnP. For example, the tensile strength of nanocomposites containing $1 \mathrm{wt} . \%$ of nanoplatelets increased by $148 \%$ versus $29 \%$, toughness increased by $466 \%$ versus $165 \%$ and elongation at break increased by $186 \%$ versus $87 \%$ for $\mathrm{FGnP}$ against $\mathrm{GnP}$ addition. According to Table 3, elongation at break of $\mathrm{PEO} / \mathrm{GnP}$ nanocomposites initially increased to $1311.8 \%$ for $\mathrm{SPE} / \mathrm{GnP}(0.1)$, and then reduced with raising the $\mathrm{GnP}$ content. However, the elongation at break of PEO/FGnP nanocomposites displayed an increment trend with FGnP content up to 1 wt.\% of FGnP (1720.8\%) and then decreased to $1438.2 \%$ for $\mathrm{PEO} / \mathrm{FGnP}(3)$. Almost a similar trend was also observed for tensile strength, yield stress and toughness of nanocomposites. Based on the preliminary studies, inherent properties of filler, its surface area and load transfer from matrix to filler play a significant role in determining the mechanical properties [62]. Considerable improvement of mechanical performance of PEO reinforced with FGnP may be attributed to better interfacial adhesion, desirable dispersion and almost complete exfoliation of this nanoparticle as evidenced by SEM and POM observations, especially at low concentrations ( $\leq 1 \mathrm{wt} . \%)$. It should be noted 
that strong interfacial interactions provide an efficient load transfer from surrounding matrix into FGnP nanosheets [63].

Conceiving the ionic conductivity, electrical conductivity and mechanical properties of nanocomposite SPEs prepared in this work, it can be inferred that SPE/FGnP nanocomposites could be a good choice to be used in flexible lithium ion batteries. Although the optimum concentration for the highest mechanical strength obtained at $1 \mathrm{wt} \%$ of FGnP, the maximum ionic conductivity adopted at $0.5 \mathrm{wt} \%$ which also showed satisfactory mechanical stability.

Table 3. Mechanical properties of neat PEO and its nanocomposites with pristine and functionalized graphene.

\begin{tabular}{|c|c|c|c|c|c|}
\hline Sample & $\begin{array}{l}\text { Young's Modulus } \\
(\mathrm{MPa})\end{array}$ & $\begin{array}{l}\text { Yield Stress } \\
(\mathrm{MPa})\end{array}$ & $\begin{array}{l}\text { Tensile Strength } \\
(\mathrm{MPa})\end{array}$ & $\begin{array}{l}\text { Toughness } \\
\left(\mathrm{MJ} / \mathrm{m}^{3}\right)\end{array}$ & $\begin{array}{l}\text { Elongation at break } \\
(\%)\end{array}$ \\
\hline PEO & $207.0 \pm 7.2$ & $6.80 \pm 0.45$ & $7.83 \pm 0.43$ & $33.4 \pm 4.6$ & $602.1 \pm 58$ \\
\hline $\mathrm{PEO} / \mathrm{GnP}(0.1)$ & $301.6 \pm 26$ & $10.8 \pm 1.11$ & $15.24 \pm 1.08$ & $140.8 \pm 23.7$ & $1311.8 \pm 35$ \\
\hline $\mathrm{PEO} / \mathrm{GnP}(0.5)$ & $359.8 \pm 25$ & $9.64 \pm 0.78$ & $12.83 \pm 0.66$ & $103.2 \pm 13.2$ & $1097.1 \pm 98$ \\
\hline $\mathrm{PEO} / \mathrm{GnP}(1)$ & $307.1 \pm 27.7$ & $8.97 \pm 0.93$ & $10.13 \pm 1.04$ & $88.66 \pm 7.6$ & $1130.1 \pm 67$ \\
\hline $\mathrm{PEO} / \mathrm{GnP}(3)$ & $344.8 \pm 25.7$ & $8.37 \pm 0.43$ & $12.98 \pm 0.68$ & $85.4 \pm 8.8$ & $1086.5 \pm 106$ \\
\hline PEO/FGnP(0.1) & $329.3 \pm 43$ & $10.66 \pm 0.21$ & $15.87 \pm 0.63$ & $129.4 \pm 3.8$ & $1010.3 \pm 82$ \\
\hline $\mathrm{PEO} / \mathrm{FGnP}(0.5)$ & $378.4 \pm 32$ & $10.47 \pm 1.76$ & $16.01 \pm 0.81$ & $131.03 \pm 15.8$ & $1212.5 \pm 62$ \\
\hline PEO/FGnP(1) & $342.4 \pm 11$ & $10.48 \pm 0.35$ & $19.38 \pm 1.06$ & $188.99 \pm 14.2$ & $1720.8 \pm 20$ \\
\hline PEO/FGnP(3) & $328.0 \pm 6.9$ & $11.61 \pm 0.52$ & $19.92 \pm 0.78$ & $184.5 \pm 24.7$ & $1438.2 \pm 118$ \\
\hline
\end{tabular}



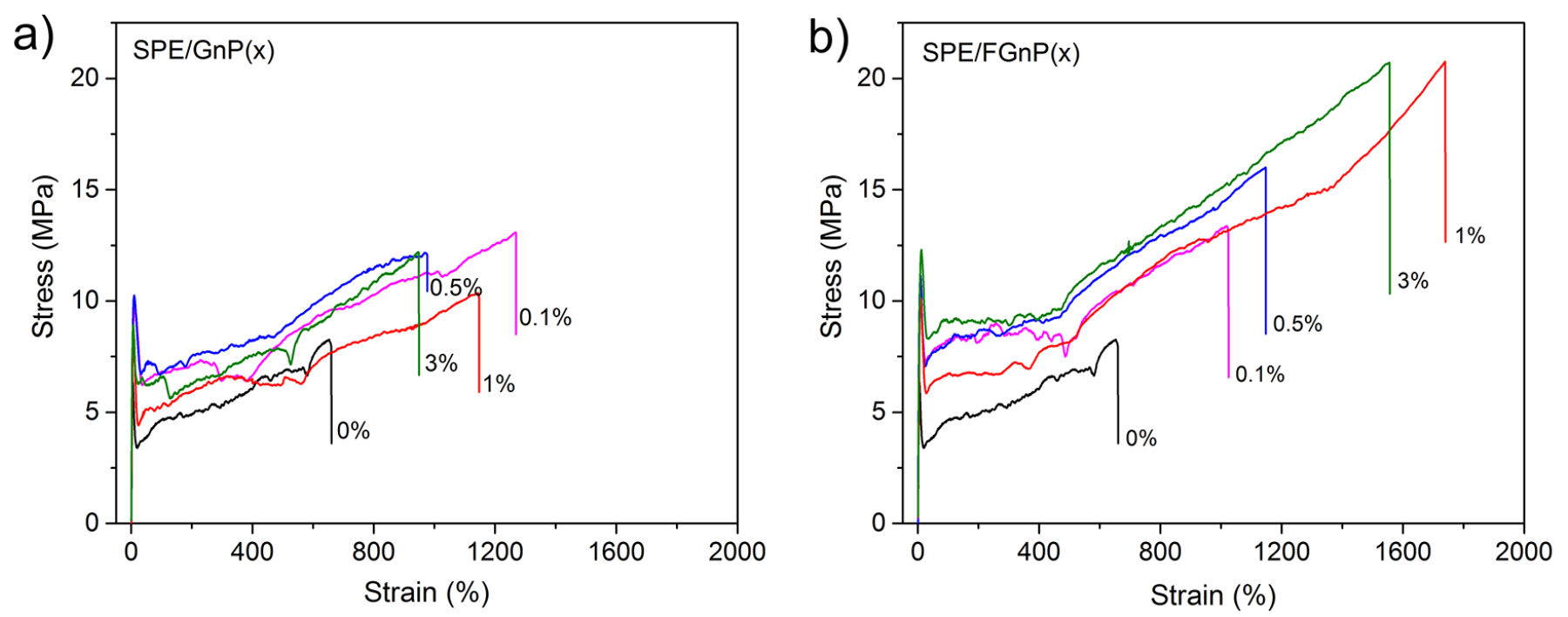

Fig. 11. Stress-strain curves of neat $\mathrm{PEO}$ and its nanocomposites: (a) $\mathrm{PEO} / \mathrm{GnP}(\mathrm{x})$, (b) $\mathrm{PEO} / \mathrm{FGnP}(\mathrm{x})$.

\section{Conclusion}

The effect of graphene nanoplatelets and its functionalization with PEG were examined on the crystalline structure, thermal behavior, ionic conductivity and mechanical properties of solid polymer electrolytes based on $\mathrm{PEO}: \mathrm{LiClO}_{4}$. By compatibilizing filler with the matrix a good dispersion of FGnP in the PEO was observed from SEM micrographs in comparison to untreated $\mathrm{GnP}$, which could provide the advantage of large surface area per unit volume. However, some aggregations of FGnP could be found at higher contents. POM images revealed the antinucleating effect of both $\mathrm{GnP}$ and $\mathrm{FGnP}$ and an increase of amorphous phase for SPE/FGnP nanocomposites. PEG molecules grafted on FGnP could interact through hydrogen bonds with oxygen atoms in PEO chains and thus disrupt the PEO crystallization. DSC analysis and XRD patterns corroborate the reduction of crystallinity in the presence of graphene nanoplatelets especially at the presence of the functionalized ones. The ionic conductivity of SPE/GnP 
nanocomposites exhibited a slight increment of about 6-fold which was independent of GnP concentration, while ionic conductivity of SPE/FGnP nanocomposite electrolytes at room temperature reached a maximum of $2.53 \times 10^{-5} \mathrm{~S} \mathrm{~cm}^{-1}(\sim 19$-fold enhancement in comparison to neat SPE) at 0.5 wt. \% of FGnP. The reduction of ionic conductivity at higher contents could be related to decrease of effective interfacial area due to aggregation of FGnPs. Higher contents of amorphous phase, enhanced concentration of free ions, further ion conducting channels via PEG grafted onto FGnP and plasticizing effect of PEG which promotes the segmental motion of PEO chains, could be expressed as possible explanations for improvement of ionic conduction. Determination of electrical conductivity proved that the nanocomposite films show insulating electrical properties. The mechanical properties of nanocomposite films including tensile strength, toughness and elongation at break were also substantially enhanced upon the addition of GnP or FGnP. The existence of interactions between FGnP and PEO leads to strong adhesion between filler and matrix to gain a better load transfer and thus superior mechanical properties in the case of FGnP. Consequently, it seems that functionalized graphene could concurrently improve the ionic conductivity and mechanical performance of solid polymer electrolytes to be used in flexible devices.

\section{Acknowledgements}

We gratefully acknowledge financial support from the Iranian National Science Foundation (INSF, Grant No. 94013014).

\section{References}


[1] G. Zhou, F. Li, H.-M. Cheng, Energy Environ. Sci. 7 (2014) 1307-1338.

[2] Y. Hu, X. Sun, J. Mater. Chem. A 2 (2014) 10712-10738.

[3] M. Kammoun, S. Berg, H. Ardebili, Nanoscale 7 (2015) 17516-17522.

[4] W.H. Meyer, Adv. Mater. 10 (1998) 439-448.

[5] F.M. Gray, Solid Polymer Electrolytes: Fundamentals and Technological Applications, Wiley, New York, 1991.

[6] Z. Xue, D. He, X. Xie, J. Mater. Chem. A 3 (2015) 19218-19253.

[7] R.C. Agrawal, G.P. Pandey, J. Phys. D. Appl. Phys. 41 (2008) 223001.

[8] S. Cheng, D.M. Smith, C.Y. Li, Macromolecules 47 (2014) 3978-3986.

[9] E. Zygadło-monikowska, Z. Florja, R. Kovarsky, S.H. Chung, S.G. Greenbaum, J. Power Sources 173 (2007) 734-742.

[10] Y.-T. Kim, E.S. Smotkin, Solid State Ionics 149 (2002) 29-37.

[11] S. Das, A. Ghosh, Electrochim. Acta 171 (2015) 59-65.

[12] T. Itoh, Y. Ichikawa, N. Hirata, T. Uno, M. Kubo, O. Yamamoto, Solid State Ionics 150 (2002) 337-345

[13] Y. Matoba, Y. Ikeda, S. Kohjiya, Solid State Ionics 147 (2002) 403-409.

[14] W. Young, J.N.L. Albert, A.B. Schantz, T.H. Epps, (2011) 8116-8123.

[15] W.-S. Young, T.H. Epps III, Macromolecules 42 (2009) 2672-2678.

[16] S. Ramesh, T. Winie, A.K. Arof, Eur. Polym. J. 43 (2007) 1963-1968. 
[17] C. Angesh, R.C. Agrawal, Y.K. Mahipal, J. Phys. D. Appl. Phys. 42 (2009) 135107.

[18] F.B. Dias, L. Plomp, J.B.J. Veldhuis, J. Power Sources 88 (2000) 169-191.

[19] J.H. Shin, K.W. Kim, H.J. Ahn, J.H. Ahn, Mater. Sci. Eng. B 95 (2002) 148-156.

[20] S.A. Suthanthiraraj, M.K. Vadivel, Ionics (Kiel). 18 (2012) 385-394.

[21] H. Zhang, J. Wang, H. Zheng, K. Zhuo, Y. Zhao, J. Phys. Chem. B 109 (2005) 26102616.

[22] J.-W. Kim, K.-S. Ji, J.-P. Lee, J.-W. Park, J. Power Sources 119 (2003) 415-421.

[23] A. Dey, S. Karan, S.K. De, J. Phys. Chem. Solids 71 (2010) 329-335.

[24] H. Kim, A.A. Abdala, C.W. Macosko, Macromolecules 43 (2010) 6515-6530.

[25] S. Zhang, P. Xiong, X. Yang, X. Wang, Nanoscale 3 (2011) 2169-2174.

[26] S. Niyogi, E. Bekyarova, M.E. Itkis, J.L. McWilliams, M.A. Hamon, R.C. Haddon, J. Am. Chem. Soc. 128 (2006) 7720-7721.

[27] P. Diwan, S. Harms, K. Raetzke, A. Chandra, Solid State Ionics 217 (2012) 13-18.

[28] S. Gao, J. Zhong, G. Xue, B. Wang, J. Memb. Sci. 470 (2014) 316-322.

[29] M. Yuan, J. Erdman, C. Tang, H. Ardebili, RSC Adv. 4 (2014) 59637-59642.

[30] T. Kuila, H. Acharya, S.K. Srivastava, B.K. Samantaray, S. Kureti, Mater. Sci. Eng. B 137 (2007) 217-224.

[31] S. Gomari, I. Ghasemi, M. Esfandeh, Mater. Res. Bull. 83 (2016) 24-34.

[32] J.F. Rabek, Experimental Methods in Polymer Chemistry: Physical Principles and Application, Wiley, 1980. 
[33] X. Li, S.L. Hsu, J. Polym. Sci. Polym. Phys. Ed. 22 (1984) 1331-1342.

[34] B.H. Stuart, Infrared Spectroscopy: Fundamentals and Applications, Wiley, 2004.

[35] T. Szabó, O. Berkesi, P. Forgó, K. Josepovits, Y. Sanakis, D. Petridis, I. Dékány, Chem. Mater. 18 (2006) 2740-2749.

[36] B.-X. Yang, J.-H. Shi, K.P. Pramoda, S.H. Goh, Nanotechnology 18 (2007) 125606125612.

[37] F. Xiang, S.M. Ward, T.M. Givens, J.C. Grunlan, Soft Matter 11 (2015) 1001-1007.

[38] S.A. Suthanthiraraj, M.K. Vadivel, Ionics (Kiel). 18 (2012) 385-394.

[39] L. Wang, W. Yang, J. Wa ng, D.G. Evans, Solid State Ionics 180 (2009) 392-397.

[40] V. Georgakilas, M. Otyepka, A.B. Bourlinos, V. Chandra, N. Kim, K.C. Kemp, P. Hobza, R. Zboril, K.S. Kim, Chem. Rev. 112 (2012) 6156-6214.

[41] C. Shen, J. Wang, Z. Tang, H. Wang, H. Lian, J. Zhang, C. Cao, Electrochim. Acta 54 (2009) 3490-3494.

[42] J.Y. Kim, H.S. Park, S.H. Kim, Polymer. 47 (2006) 1379-1389.

[43] M. El Achaby, F. Arrakhiz, S. Vaudreuil, A. el Kacem Qaiss, M. Bousmina, O. Fassi-Fehri, Polym. Compos. 33 (2012) 733-744.

[44] T. Chatterjee, A.T. Lorenzo, R. Krishnamoorti, Polymer. 52 (2011) 4938-4946.

[45] A. Adhikari, K. Lozano, J. Polym. Res. 18 (2011) 875-880.

[46] N. Rahmansyah, C. Lo, C. Syu, C. Lee, J. Appl. Polym. Sci. 122 (2011) 1236-1244.

[47] C. Sun, T.A. Zawodzinski Jr, W.E. Tenhaeff, F. Ren, J.K. Keum, S. Bi, D. Li, S.-K. Ahn, 
K. Hong, A.J. Rondinone, J.-M.Y. Carrillo, C. Do, B.G. Sumpter, J. Chen, Phys. Chem. Chem. Phys. 17 (2015) 8266-8275.

[48] B.-K. Choi, Solid State Ionics 168 (2004) 123-129.

[49] W. Wieczorek, D. Raducha, A. Zalewska, J.R. Stevens, J. Phys. Chem. B 102 (1998) 8725-8731.

[50] C. Tang, K. Hackenberg, Q. Fu, P.M. Ajayan, H. Ardebili, Nano Lett. 12 (2012) 11521156.

[51] D. Zhou, X. Mei, J. Ouyang, J. Phys. Chem. C 115 (2011) 16688-16694.

[52] B. Scrosati, Applications of Electroactive Polymers, Chapman and Hall, London, 1993.

[53] Y. Xue, Y. Liu, F. Lu, J. Qu, H. Chen, L. Dai, J. Phys. Chem. Lett. 3 (2012) 1607-1612.

[54] S. Vadukumpully, J. Paul, N. Mahanta, S. Valiyaveettil, Carbon N. Y. 49 (2011) 198-205.

[55] J.A. Torres, P.F. Nealey, J.J. De Pablo, Phys. Rev. Lett. 85 (2000) 3221.

[56] B.K. Money, K. Hariharan, J. Swenson, J. Phys. Chem. B 116 (2012) 7762-7770.

[57] A. Udomvech, T. Kerdcharoen, T. Osotchan, Chem. Phys. Lett. 406 (2005) 161-166.

[58] S.H. Xie, Y.Y. Liu, J.Y. Li, Appl. Phys. Lett. 92 (2008) 243121.

[59] J. Du, L. Zhao, Y. Zeng, L. Zhang, F. Li, P. Liu, C. Liu, Carbon N. Y. 49 (2011) 10941100.

[60] S. Stankovich, D.A. Dikin, R.D. Piner, K.A. Kohlhaas, A. Kleinhammes, Y. Jia, Y. Wu, S.T. Nguyen, R.S. Ruoff, Carbon N. Y. 45 (2007) 1558-1565.

[61] G. Eda, G. Fanchini, M. Chhowalla, Nat. Nanotechnol. 3 (2008) 270-274. 
[62] F.H. Gojny, K. Schulte, Compos. Sci. Technol. 64 (2004) 2303-2308.

[63] S.-Y. Fu, X.-Q. Feng, B. Lauke, Y.-W. Mai, Compos. Part B Eng. 39 (2008) 933-961. 


\section{Figure Captions}

Fig. 1 The procedure for preparation of PEG-grafted graphene (FGnP) from pristine graphene $(\mathrm{GnP})$.

Fig. 2 FT-IR spectra of (a) neat GnP, (b) GnP-COOH, (c) FGnP and (d) pure PEG400.

Fig. 3 SEM micrographs of cryofractured surfaces of a) $\mathrm{SPE} / \mathrm{GnP}(0.5)$ and b) SPE/FGnP(0.5), the inset shows $\mathrm{SPE} / \mathrm{FGnP}(3)$ sample.

Fig. 4 Surface SEM images of a) SPE, b) SPE/GnP(0.1), c) SPE/GnP(0.5), d) SPE/GnP(1), e) $\mathrm{SPE} / \mathrm{GnP}(3)$, f) $\mathrm{SPE} / \mathrm{FGnP}(0.1)$, g) SPE/FGnP(0.5), h) SPE/FGnP(1), i) SPE/FGnP(3).

Fig. $5 \mathrm{XRD}$ patterns of a) $\mathrm{SPE} / \mathrm{GnP}(\mathrm{x})$ and $b) \mathrm{SPE} / \mathrm{FGnP}(\mathrm{x})$ nanocomposites. Insets show pure GnP and FGnP.

Fig. 6 The obtained results from DSC analysis: a) crystallization temperature $\left.\left(T_{\mathrm{c}}\right), \mathrm{b}\right)$ melting temperature $\left.\left(T_{\mathrm{m}}\right), \mathrm{c}\right)$ degree of crystallinity $\left(X_{\mathrm{c}}\right)$, and d) glass transition temperature $\left(T_{\mathrm{g}}\right)$ of SPE and its nanocomposites containing GnP (solid square) and FGnP (solid circle) as a function of filler content.

Fig. 7 Polarized optical microscopy images of a) PEO, b) SPE, c) $\operatorname{SPE} / \mathrm{GnP}(0.1)$, d) $\mathrm{SPE} / \mathrm{FGnP}(0.1)$, e) SPE/GnP(1) and f) SPE/FGnP(1).

Fig. 8 Dissociation factor of salt ions (fraction of free anions) based on FT-IR analysis for $\mathrm{SPE} / \mathrm{GnP}$ and SPE/FGnP nanocomposites with various filler content.

Fig. 9 The ionic conductivity of SPE/GnP and SPE/FGnP nanocomposites with various filler loadings at room temperature.

Fig. 10 Schematics of PEO: $\mathrm{LiClO}_{4}$ electrolytes without (a) and with (b) $\mathrm{FGnP}$.

Fig. 11 Stress-strain curves of neat $\mathrm{PEO}$ and its nanocomposites: (a) $\mathrm{PEO} / \mathrm{GnP}(\mathrm{x})$, (b) 
$\mathrm{PEO} / \mathrm{FGnP}(\mathrm{x})$.

Table captions

Table 1. Degree of crystallinity of nanocomposite electrolytes based on XRD.

Table 2. Electrical conductivity of neat $\mathrm{PEO}, \mathrm{PEO} / \mathrm{GnP}(\mathrm{x})$ and $\mathrm{PEO} / \mathrm{FGnP}(\mathrm{x})$ nanocomposites.

Table 3. Mechanical properties of neat PEO and its nanocomposites with pristine and functionalized graphene. 

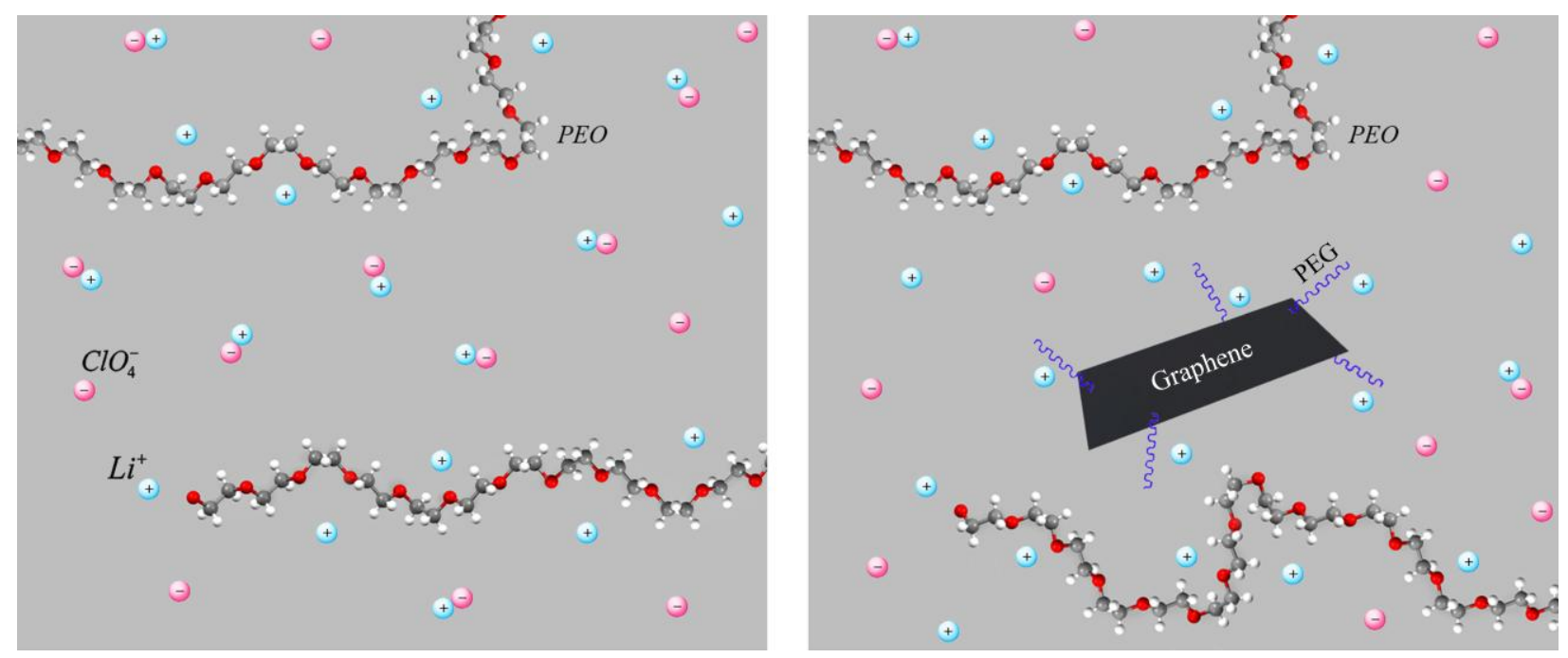